\title{
Desafios da organização pedagógica e curricular diferenciada em uma escola do campo do Município da Transamazônica - Pará
}

Challenges of differentiated pedagogical and curricular organization in a rural school in the city of Transamazônica - Pará

Irlanda do Socorro de Oliveira Miléo

Raquel da Silva Lopes

Célio Lima Machado

\begin{abstract}
Resumo: Este artigo objetiva analisar, ainda que de maneira introdutória, a compreensão e a postura dos profissionais da educação quanto a importância do desenvolvimento de um currículo diferenciado no contexto socioeducativo escolar situada em uma comunidade rural, de modo a atender às demandas identitárias dos diferentes sujeitos coletivos que vivem e trabalham no campo. Problematiza se é possível elaborar um currículo diferenciado nas escolas do campo do Município de Placas/PA; e quais estratégias são necessárias para que práticas educativas diferenciadas orientem as propostas curriculares dessas instituições de ensino. $O$ estudo de cunho qualitativo ocorreu em uma escola pública da rede de ensino municipal, com a participação de um docente que atua nas turmas dos anos finais do Ensino fundamental, da coordenadora pedagógica responsável pelo acompanhamento da escola investigada, e ainda, a direção e coordenação da Escola Polo. Os resultados apontam para a existência de um currículo escolar restrito às adaptações realizadas pelos docentes a partir das matrizes curriculares oficiais elaboradas pela Secretaria Municipal de Educação local, sem que seja oportunizada a incorporação efetiva de temáticas que favoreçam práticas socioeducativas que valorize os saberes tradicionais das famílias camponesas e seus modos de vida, evidenciando uma organização pedagógica das escolas do campo destoada das demandas formativas que respeite as identidades socioculturais existentes no campo.
\end{abstract}

Palavras chave: Currículo diferenciado. Práticas socioeducativas. Projeto Pedagógico.

\begin{abstract}
This article aims to analyze, albeit in an introductory manner, the understanding and attitude of education professionals regarding the importance of developing a differentiated curriculum in the school socio-educational context located in a rural community, in order to meet the identity demands of different collective subjects who live and work in the field. It questions whether it is possible to develop a differentiated curriculum in rural schools in the municipality of Placa / PA; and what strategies are necessary for differentiated educational practices to guide the curricular proposals of these educational institutions. The qualitative study took place in a public school in the municipal education network, with the participation of a teacher who works in the final years of elementary school, the pedagogical coordinator responsible for monitoring the investigated school, and also the direction and coordination Polo School. The results point to the existence of a school curriculum restricted to the adaptations made by the teachers from the official curricular matrices elaborated by the local Municipal Department of Education, without allowing the effective incorporation of themes that favor socio-educational practices that value the traditional knowledge of families peasants and their ways of life, showing a pedagogical organization of rural
\end{abstract}


schools that is out of touch with training demands that respects the socio-cultural identities existing in the countryside.

Keywords: Differentiated curriculum. Socio-educational practices. Pedagogical project.

\section{Introdução}

As especificidades do currículo proposto às escolas do campo têm fomentado diferentes debates sobre sua materialidade no cenário educacional brasileiro, marcado quase sempre, por modelos urbanocêntricos de desenvolvimento distantes da realidade social dos sujeitos coletivos que constituem o território rural, espaço de vida e de trabalho das famílias campesinas (MOLINA; SÁ, 2012; HAGE, 2011).

Essas dissonâncias se acentuam quando as discussões se voltam ao espaço escolar às práticas educativas ali desenvolvidas, pois conforme pesquisas apontam (HAGE, 2011; ARROYO, 2009), o ensino que é ofertado às crianças, jovens e adultos geralmente tendem a ser substrato daquele materializado nas escolas urbanas; deixando de considerar as especificidades culturais e identitárias próprias dos sujeitos do campo. Quanto às práticas pedagógicas, seguem ainda uma lógica municiada pelos órgãos gestores no sentido de proporcionar as "adaptações" dos conteúdos de acordo com a realidade dos alunos, atribuindo ao docente toda responsabilidade de gestar o currículo sem que sejam dadas condições favoráveis para que a ação educativa seja executada com qualidade.

É certo que existem diferentes fatores que podem fragilizar as práticas pedagógicas, principalmente quando priorizam conteúdos escolares fragmentados e descontextualizados, considerando mais o cumprimento das matrizes curriculares oficiais do que as singularidades culturais e identitárias que encontram contexto das escolas do campo; aspectos que comprometem a qualidade das ações formativas propostas, pois ainda verifica-se a ausência de política de formação que contemple as especificidades do modo de vida das pessoas que vivem no e do campo. Nesse sentido, é preciso um ambiente escolar acolhedor que proporcione situações de aprendizagens significativas que respeitem a diversidade sociocultural como direito dos que ali se encontram. (ARROYO, 2006). 
As práticas curriculares representam é um campo de conhecimento transpassado por relações de poder que influenciam a organização do trabalho escolar, marcando o tempo e espaço escolar, ou seja, "o currículo é sempre o resultado de uma seleção: de um universo mais amplo de conhecimentos e saberes, seleciona-se aquela parte que vai constituir, precisamente, o currículo" (SILVA, 2009, p. 15). Por ser um espaço político e cultural que traz em si desafios e dilemas quanto a proposição de construção de uma educação diferencia, cujo fundamento assenta na defesa do reconhecimento e valoração do patrimônio cultural, perspectivando nos dizeres de Caldart (2002, p. 23) ações educativas "que forme e cultive identidades, auto-estima, valores, memória, saberes, sabedoria; que enraíze sem necessariamente fixar as pessoas em sua cultura, seu lugar, seu modo de pensar, de agir, de produzir".

Isso implica em assegurar que a construção da proposta pedagógica da escola seja produto de um trabalho coletivo, resguardando o direito da comunidade local em participar dos processos decisórios juntamente com alunos, professores, equipe técnico-pedagógica e demais funcionários da escola (VEIGA, 2005). É preciso também garantir que os representantes dos órgãos gestores da educação - Secretaria Municipal de Educação (SEMEC), Conselho Escolar e movimentos sociais do campo - se façam presentes, atendendo assim, todas as peculiaridades e realidades que estão postas à sua volta, e com isso, contemplar todas as suas realidades e interesse da comunidade.

Nessa linha de raciocínio, a pesquisa em tela propõe refletir se é possível elaborar um currículo diferenciado em uma escola do campo do Município de Placas/PA; e quais estratégias são necessárias para que práticas educativas diferenciadas orientem as propostas curriculares dessas instituições de ensino. Tem como objetivo central analisar, ainda que de maneira introdutória, a compreensão e a postura dos profissionais da educação quanto a importância do desenvolvimento de um currículo diferenciado no contexto socioeducativo escolar situada em uma comunidade rural, de modo a atender às demandas identitárias dos diferentes sujeitos coletivos que vivem e trabalham no campo

O estudo ora apresentado fundamenta-se em uma pesquisa qualitativa, que segundo Minayo (2002, p. 21) se refere àquela que "se preocupa com um 
nível de realidade que não pode ser quantificado", e "trabalha com o universo de significados, motivações, aspirações, crenças, valores e atitudes". A pesquisa qualitativa viabiliza a apresentação de resultados particulares de um determinado contexto marcado por um universo de significados, tradições, valores, "o que corresponde a um espaço mais profundo das relações, dos processos e dos fenômenos que não podem ser reduzidos a operacionalização de variáveis" (MINAYO, 2002, p. 22).

A pesquisa de campo ocorreu na Escola Municipal de Ensino Fundamental Mec/Seduc 185 D (anexa à Escola Mec Seduc 200-A), localizada na vicinal do lama, Comunidade São Judas Tadeu - km 185, BR 230Transamazônica, sentido Itaituba-Altamira, a $55 \mathrm{Km}$ da sede do município de Placas/PA. Foi adotado como técnica para a coleta dos dados o questionário com roteiro estruturado, por este permitir maior tempo para os participantes responderem às perguntas propostas. Conforme aponta Gil (2001, p.128), este pode ser entendido "como a técnica de investigação composta por um número mais ou menos elevado de questões apresentadas por escrito às pessoas, tendo por objetivo o conhecimento de opiniões, crenças, sentimentos, interesses, expectativas, situações vivenciadas etc".

Os sujeitos que participaram da pesquisa foram um docente que atua nas turmas dos anos finais do Ensino fundamental com as disciplinas de Língua Portuguesa e Língua Inglesa, a coordenadora pedagógica responsável pelo acompanhamento da escola investigada, e a diretora e coordenadora pedagógica da escola polo - Mec Seduc 200-A, que responde administrativa e pedagogicamente pelas escolas anexas.

\section{Educação do Campo e as práticas pedagógicas e curriculares: valorização das culturas e identidades dos sujeitos coletivos no espaço escolar}

A discussão no cenário brasileiro referente à educação do campo como direito articula-se à defesa de um processo educativo que incorpore e valorize as diferentes identidades socioculturais dos sujeitos do campo; sujeitos que se movimentam e se formam na luta pela terra vislumbrando um novo projeto de sociedade alicerçado na luta pela Reforma Agrária. Segundo Arroyo (2009), essas preocupações resultam de um processo histórico, contraditório e desigual 
que imprime suas marcas nas escolas e no tipo de educação pensada direcionada à população camponesa, vistas como pessoas ignorantes, atrasadas, sem cultura, que perdurou muitas décadas no Brasil. Uma educação rural idealizada pela elite ruralista com a finalidade de cumprir as designações legais, porém, organizada pedagogicamente aos moldes do currículo da cidade sem que houvesse a preocupação com a qualidade do ensino ofertado, pois,

[...] para a escolinha rural qualquer coisa serve. Para mexer com a enxada não há necessidade de muitas letras. Para sobreviver com uns trocados, para não levar manta na feira, não há necessidade de muitas letras. Em nossa história domina a imagem de que a escola do campo tem que ser apenas a escolinha rural das primeiras letras. A escolinha cai não cai, onde uma professora que quase não sabe ler ensina alguém a não saber quase ler (ARROYO, 2009, p. 71).

Em decorrência das inúmeras dificuldades de escolarização enfrentadas pelas populações do campo, decorrentes das estruturas precárias e isoladas, currículo fragmentado e desconexo com os saberes tradicionais campesinos, professores sem formação adequada para atuar nos níveis de ensino e altos índices de reprovação e evasão, concorreu para que um conjunto de instituições e organizações sociais e educacionais da sociedade, como universidades públicas, sindicatos e inúmeros movimentos sociais ${ }^{1}$ como o Movimento dos Sem Terra, promovessem uma série de ações reivindicatórias articuladas com trabalhadores rurais, visando reverte a problemática da escola rural de forma proposita (CALDART, 2004; FERNANDES, 2006). Essa luta organizada recebeu o nome de "Movimento de Educação do Campo no Brasil", e deu início à construção de uma proposta em que os campesinos passaram a assumir a condição de sujeitos de seu próprio projeto educativo.

Nesse contexto apoiados pelo coletivo de sujeitos defensores dos direitos, dos interesses, da política, da cultura e dos modos de produção do povo camponês, de acordo com Fernandes (2006) forjou-se na década de 1990, o

\footnotetext{
1. Como por exemplo, o Movimento dos Sem Terra (MST), o Movimento dos Atingidos pelas Barragens (MAB), o Movimento das Mulheres Camponesas (MMC), o Movimento dos Pequenos Agricultores (MPA), e ainda, sindicatos e federações estaduais vinculados à Confederação dos Trabalhadores da Agricultura (CONTAG), o Movimento de Mulheres Trabalhadoras Rurais (vide a Marcha das Margaridas), a Rede de Educação do Semi-Árido Brasileiro (RESAB), Comissão Pastoral da Terra (CPT), dentre outros. Para maior detalhamento, ver Caldart (2004); Fernandes (2006);
} 
conceito de Educação do Campo pautado na articulação do campo educativo para valorização dos saberes culturais e da produção das condições de existência social dos trabalhadores e trabalhadoras rurais:

A Educação do Campo nasceu dos pensamentos, desejos e interesses dos sujeitos do campo, que nas últimas décadas intensificaram suas lutas, especializando-se e territorializandose formando territórios concretos e imateriais, constituindo comunidades e politicas, determinando seus destinos na construção de suas ideologias, suas visões de mundo. A Educação Rural nasceu da cabeça dos ruralistas como forma de subordinar os camponeses, de reservar a eles um controlado espaço nas politicas de educação para "civilizar" e manter a subordinação. Assim, por quase um século, a Educação Rural não promoveu politicas autênticas, não propôs o desenvolvimento educacional campesinato. Nesse tempo, foi o espaço de controle politico dos ruralistas que determinavam como os camponeses deveriam pensar o seu mundo, conforme a visão dos ruralistas (FERNANDES, 2006, p. 16).

Nessa perspectiva a Educação Básica do Campo não pode ser concebida sem a participação da diversidade de sujeitos de diferentes matrizes étnicas existentes no meio rural; sem que seja reconhecida como dimensões centrais do processo pedagógico, seus saberes e modos de vida como base fundante de seu desenvolvimento humano. Isso implica em uma compreensão a respeito das práticas pedagógicas e curriculares diferenciadas, inovadoras; pois $\mathrm{o}$ ato educativo não pode estar restrito e limitado ao espaço institucional. O campo se constitui em um território de lutas sociais, de produção de saberes, de poderes e transformação (ARROYO, 2009; HAGE, 2011), sendo importante que os profissionais da educação que atuam nas escolas rurais entendam a relação campo-cidade como condições democráticas que se complementam, e não mais o espaço rural como extensão do urbano.

Caldart (2008) defende que a ênfase na educação pretendida pelos movimentos sociais transcende 0 entendimento de transmissão de conhecimentos, fundamentando-se em uma tradição pedagógica orientada pelo como princípio educativo, na luta pelas condições de acesso e permanência à escola no e do campo; e na construção de uma proposta pedagógica alicerçada em saberes e técnicas agropecuárias articuladas ao trabalho e à cultura do 
campo. Essa compreensão também é destacada por Munarim e Locks (2012, p.

08) quando argumentam que:

\begin{abstract}
Nesse processo preconiza-se uma educação "no campo", porque o povo tem o direito de ser educado onde vive; "do campo", porque o povo tem direito a uma educação pensada desde o seu lugar e com a sua participação, e que seja vinculada a sua cultura e as suas necessidades. Esta nova concepção de educação, dentre seus princípios, se direciona no sentido da construção da identidade e autonomia das populações do campo. Sustenta o entendimento da relação de complementaridade no binômio campo-cidade, onde uma faceta não vive sem a outra. Desse modo, a educação escolar deve evitar tanto a visão urbanocêntrica quanto o ruralismo. São princípios pedagógicos defendidos por esse Movimento que as práticas educativas nas escolas devem levar em conta 0 contexto dos sujeitos do campo, em termos de sua cultura específica, a maneira de ver e se relacionar com o tempo, o espaço, o meio ambiente, e o modo de viver e de organizar o trabalho.
\end{abstract}

Nessa assertiva, as práticas educativas, segundo aponta Caldart (2010) precisam fundamentar-se na concepção de ser humano e devem transformar as escolas tradicionais rurais em escolas do campo, de modo a propiciar formas alternativas de estreitar os laços entre comunidade local e a escola; cultivar a vivência de estudos coletivos, possibilitando a experiência da gestão coletiva na escola; além de buscar superar a dicotomia entre teoria e prática. Arroyo (2012) argumenta que aos docentes precisa ser disponibilizada uma formação plural que os instrumentalize a entender a complexidade da vida no campo, com expectativas de atender as demandas formativas das famílias que vivem no e do campo, formação essa que deve estar em consonância com a função política da escola do campo; quanto à escola,

Ela deve ser espaço em que sejam incorporados os saberes da terra, do trabalho e agricultura camponesa; em que as especificidades de ser-viver a infância-adolescência, a juventude e a vida adulta no campo sejam incorporadas nos currículos e propostas educativas; em que os saberes, concepções de história, de sociedade, de libertação aprendidos nos movimentos sociais façam parte do conhecimento escolar. (ARROYO, 2012, p. 363). 
Com base nesses posicionamentos, a formação dos professores e as práticas pedagógicas devem refletir uma ação educativa consciente e transformadora, assentada numa perspectiva de (re)construir e ressignificar a educação para a cidadania dos educandos, articulando as diferentes demandas e reivindicações dos coletivos de forma democrática.

\section{O Projeto Pedagógico nas Escolas do Campo: desafios para a construção de um currículo diferenciado}

O desafio que se coloca na construção dessa proposta como processo de produção social e coletiva é compreender ato educativo para além do modelo seriado de organização curricular conservadora, própria da sociedade moderna, que apresenta os conhecimentos de forma segmentada e descontextualizada. Como destaca Gimeno Sacristán (2000), é indispensável conceber o currículo como uma construção social que expressa ações vinculadas à cultura, sociedade, política e economia; e, por ser um campo em circulam discursos, também produz e institui identidades, significados e saberes,

O currículo acaba numa prática pedagógica [...]. Sendo a condensação ou expressão da função social e cultural da instituição escolar, é lógico que, por sua vez, impregne todo tipo de prática escolar. O currículo é o cruzamento de práticas diferentes e se converte em configurador, por sua vez, de tudo o que podemos denominar como prática pedagógica nas aulas e nas escolas (SACRISTÁN, 2000, p. 26).

A despeito das especificidades identitárias dos sujeitos coletivos do campo, essa questão está garantido na Lei de Diretrizes e Bases da Educação Nacional - LDB, Lei № 9.394/96, quando estabelece no Artigo 28, que a organização pedagógica das escolas do campo em escolar devem integrar e respeitar a particularidades em seus contextos, considerando a realidade e os interesses da população campesina, a partir de:

I - conteúdos curriculares e metodologias apropriadas às reais necessidades e interesses dos alunos da zona rural;

II - organização escolar própria, incluindo adequação do calendário escolar às fases do ciclo agrícola e às condições climáticas; 
III - adequação à natureza do trabalho na zona rural (BRASIL, 1996).

No intuito de avançar na luta pela defesa de políticas públicas especificas para as populações do campo, os movimentos sociais pressionaram o Poder Público no sentido de uma educação que contemplasse a participação dos sujeitos que vivem no e do campo, articulando a garantia dos direitos sociais e o respeito com à diversidade humana e cultural existentes nesse território, por meio da Resolução 1/2002 - CNE/CEB, foram aprovadas as Diretrizes Operacionais para a Educação Básica das Escolas do Campo, compõem um conjunto de princípios e de procedimentos com a finalidade de adequar o projeto institucional das escolas do campo, estabelecendo no Art. $5^{\circ}$ que as propostas pedagógicas, em concordância com o estabelecido na LDB, deverão contemplar "a diversidade do campo em todos os seus aspectos: sociais, culturais, políticos, econômicos, de gênero, geração e etnia" (BRASIL, 2002).

Para legitimar e consagrar essas orientações as Diretrizes Curriculares Nacionais Gerais para a Educação Básica de 2010 estabelecem, em sua Seção IV, artigo 35, orientações destinada a essa modalidade de ensino ao prever as adequações necessárias ao modo de vida das populações campesinas, e ainda defini como princípios essências à organização da ação pedagógica das escolas do campo:

I - conteúdos curriculares e metodologias apropriadas às reais necessidades e interesses dos estudantes da zona rural;

II - organização escolar própria, incluindo adequação do calendário escolar às fases do ciclo agrícola e às condições climáticas;

III - adequação à natureza do trabalho na zona rural (BRASIL, 2010a, p. 12).

Esses aspectos estabelecidos nessa Resolução apresentam melhorias quanto ao projeto pedagógico e às práticas curriculares a serem desenvolvidas no chão das escolas do campo, e ganham força por outras legislações complementares que visam fortalecer a educação do campo, a exemplo do Parecer $n^{\circ}$ 1/2006 que reconhece os Dias Letivos da Alternância, também homologado pela CEB; da Resolução CNE/CEB n²/2008; e Decreto $n^{\circ} 7.352$, 
de 4 de novembro de 2010, que dispõe sobre a Política Nacional de Educação do Campo e sobre o Programa Nacional de Educação na Reforma Agrária/PRONERA (CALDART, 2004; FERNANDES, 2006).

Nesse sentido, pensar o currículo como elemento de ressignificação da práxis educativa e do próprio espaço escolar implica, necessariamente, buscar inovar a própria concepção do projeto pedagógico, buscando dar um sentido de compromisso social e coletivo à organização do trabalho pedagógico, considerando as contradições que marcam a escola, as diferentes identidades socioculturais ali presentes, a busca pela melhoria da qualidade do ensino e a democratização de sua gestão. De acordo com Veiga (2005, p. 38):

O projeto pedagógico, ao se constituir em processo participativo de decisões, preocupa-se em instaurar uma forma de organização do trabalho pedagógico que desvele os conflitos e as contradições, buscando eliminar as relações competitivas, corporativas e autoritárias, rompendo com a rotina do mando pessoal e racionalizado da burocracia e permitindo relações horizontais no interior da escola.

Ao abordar a questão do projeto político pedagógico para as escolas do campo, Caldart (2004) chama atenção para aspectos que considera essenciais para garantir a educação do campo diferenciada e democrática, visto que os projetos educativos não podem ser elaborados a partir de uma única realidade para todos os povos campesinos como estes apresentassem uma única identidade. Isso seria incorrer no equívoco de tentar uniformizar contextos diversos. Ao contrário, as propostas pedagógicas entendidas como construto sociohistórico têm que estar articulada às demandas e particularidades de cada comunidade, localidade, território, ou seja, esse documento precisa ser deve ser elaborado buscando atender as especificidades e particularidades desse cenário multicultural. Nessa assertiva, a autora destaca que:

Este desafio se desdobra em três tarefas combinadas: manter viva a memória da Educação do Campo, continuando e dinamizando sua construção e reconstrução pelos seus próprios sujeitos; identificar as dimensões fundamentais da luta política a ser feita no momento atual; e seguir na construção do projeto político e pedagógico da Educação do Campo (CALDART, 2004, p. 16). 
Desse modo, pensar o currículo e a proposta pedagógica das escolas do campo pressupõe criar espaços de debates de modo a possibilitar a participação das famílias, das comunidades, dos movimentos sociais permanente e democraticamente.

\section{A Organização pedagógica da escola do campo pesquisada: Reflexões as percepções dos sujeitos participantes sobre as práticas pedagógicas e curriculares}

A pesquisa que subsidiou as reflexões aqui apresentadas foi realizada na Escola Municipal de Ensino Fundamenta Mec/Seduc 185 D, Município de Placas/PA. Localizada na vicinal do Lama, a $45 \mathrm{~km}$ sentido Rurópolis, atende a população de uma comunidade cuja base econômica é a agricultura famíliar, criação de bovinos de leite e de corte e lavoura cacaueira. De acordo com informações dos participantes da pesquisa, a comunidade teve sua primeira escola na década de 1970 para atender as crianças, filhos dos colonos que foram morar na Transamazônica, por meio do Projeto de Colonização organizado pelo Instituto Nacional de Reforma Agrária (INCRA), órgão do governo federal. Em decorrência do aumento da população local, a estrutura da escola foi ampliada.

Atualmente, a instituição de ensino é anexa da Escola Mec Seduc 200-A (Escola Polo), atende uma média de 50 alunos $^{2}$, dispõe de 4 professores, 1 servente e 2 motoristas responsáveis pelo transporte escolar dos estudantes. Seu espaço físico (figura 1) tem duas salas de aula, uma secretaria que também funciona sala de leitura, um banheiro feminino e um masculino. A escola não conta com uma biblioteca, somente com uma sala de leitura que divide o espaço com a secretaria escolar, que possui um pequeno acervo.

\footnotetext{
${ }^{2}$ Dados do ano de 2019 coletados na escola.
} 


\section{Figura 1 - Escola Municipal de Ensino Fundamental Mec/Seduc 185 D}

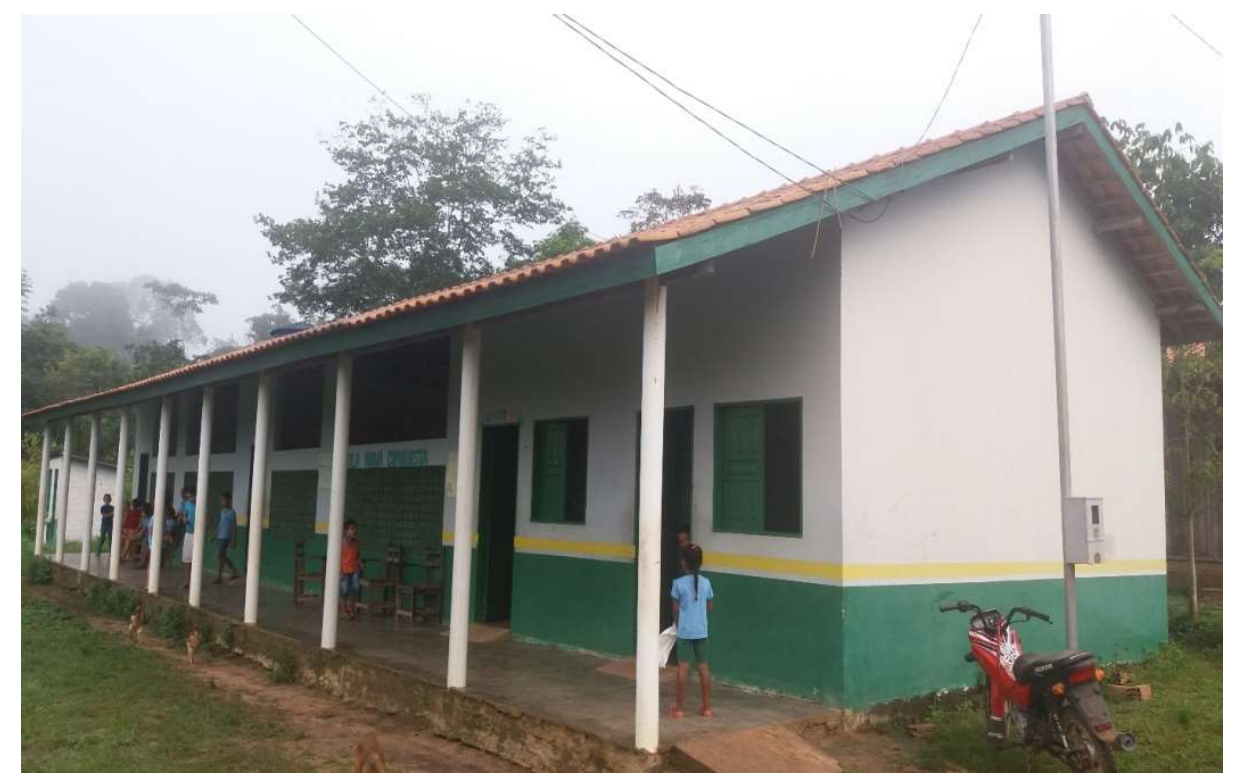

Fonte: Arquivo pessoal dos autores

Participaram de nossas investigações quatro profissionais da educação que atuam tanto na escola investigada quanto na escola polo. A primeira participante foi Márcia de Oliveira Rosa, Coordenadora Pedagógica e professora de Educação Infantil e anos iniciais do Ensino Fundamental da Escola Polo Escola Mec Seduc 200-A. É professora há 20 anos, tem formação em Pedagogia com pós-graduação em Gestão e Coordenação Pedagógica e Psicopedagogia Clinica Institucional. Outra entrevistada foi Gisele da Silva Coelho, Diretora Escolar (Escola Polo e Anexas) é licenciada em Língua Portuguesa e Literatura Brasileira, Pós-Graduada em Gestão Escolar, e atua na Educação do Campo desde 1996.

Em relação ao professor Gilberto Borges, este atua no magistério há 17 anos; é licenciado em Letras com Pós-Graduação em Línguas Estrangeiras atua com as disciplinas de Língua Portuguesa e Língua Inglesa nas turmas dos anos finais do Ensino Fundamental na Escola Mec Seduc 185 A e também na Escola 200 A. Já a docente Rosângela Pereira Nunes trabalha na Escola do Campo há 18 anos e assumiu a Coordenação Pedagógica das Escolas Anexas no ano de 2019; é formada em Pedagogia e Ciências da Natureza com especialização em Gestão Escolar, Orientação e Supervisão. As informações sobre as 
denominações que identificam os relatos dos participantes dessa pesquisa estão descritas no quadro 1.

Quadro 1: Identificação dos Sujeitos da Pesquisa

\begin{tabular}{|l|l|l|}
\hline Cargo/Função & Nome* & Denominação \\
\hline $\begin{array}{l}\text { Coordenadora Pedagógica da } \\
\text { Escola Polo. }\end{array}$ & $\begin{array}{l}\text { Márcia de } \\
\text { Oliveira Rosa }\end{array}$ & Coord. Ped. EP \\
\hline Diretora Escolar (Polo e Anexas) & $\begin{array}{l}\text { Gisele da Silva } \\
\text { Coelho }\end{array}$ & Diretora Escolar \\
\hline $\begin{array}{l}\text { Professor de Língua Portuguesa e } \\
\text { Estrangeira }\end{array}$ & Gilberto Borges & Professor LP/LE \\
\hline $\begin{array}{l}\text { Coordenadora Pedagógica das } \\
\text { Escolas Anexas }\end{array}$ & $\begin{array}{l}\text { Rosângela } \\
\text { Pereira Nunes }\end{array}$ & Coord. Ped. EA \\
\hline
\end{tabular}

* Os nomes aqui apresentados dos sujeitos participantes da pesquisa são fictícios.

Ao tratamos sobre questões relacionadas às populações do campo, de modo geral, percebemos que o campo brasileiro constitui-se em um espaço heterogêneo de culturas e identidades, marcado historicamente por lutas e mobilizações organizadas com objetivos de garantir seus direitos ao acesso às politicas sociais, como o direito à terra, ao trabalho, à moradia digna, à educação e saúde de qualidade. Esses aspectos suscitam questionamentos quanto à organização do trabalho pedagógico das escolas do campo e direcionaram o estudo ora apresentado

Em nossa inserção no espaço escolar, detectamos que por se tratar de uma escola anexa, a mesma não possui o Projeto Pedagógico próprio. A coordenadora Rosângela Pereira Nunes nos informou que as escolas do campo do município de Placas/PA seguem o currículo escolar que é elaborado pela Secretaria Municipal de Educação de Placas (SEMEC).

Os alunos têm acesso a alguns tipos de materiais impressos como: propagandas, noticiários, e demais materiais retirados de sites da internet, que são utilizados pelo professor para trabalhar os gêneros textuais.

Quanto ao planejamento dos conteúdos dirigidos às escolas do campo, esses são organizados por série na matriz curricular, o que é contraditório, pois os estabelecimentos de ensino localizados no meio rural têm sua organização pedagógica multisseriada, esse aspecto não é considerado pela SEMEC local quanto a elaboração da proposta curricular encaminhada às mesmas, cabendo ao professor fazer esses ajustes, o que dificulta o trabalho docente. 
Arroyo (2006) tece considerações a respeito dessa forma de organização da escola do campo e argumenta que esse arranjo pedagógico, seja seriado ou multisseriado, não considera as "múltiplas temporalidades éticas, cognitivas, identitárias" presentes nesse espaço educativo. Sua defesa fundamenta-se na diversidade de temporalidades que a escola precisa respeitar,

Classificar a escola do campo como multisseriadas leva a uma visão sempre negativa e a tendência dos professores a organizar a escola por séries, apesar de terem idades tão diferentes. Leva a recortar os conhecimentos: "agora trabalho o conteúdo da primeira série, agora com vocês o da segunda...". Isso é um caos! A pergunta: vamos acertar com uma organização da escola do campo que não seja cópia da escola seriada da cidade que queremos já destruir? Eu sou um grande defensor que esta escola seriada seja desconstruída e que se organize a partir das temporalidades humanas (ARROYO, 2006, p. 113-114).

A preocupação com as "adaptações" do currículo das escolas do campo acabam se tornando a preocupação central da prática pedagógica, fazendo com que os esforços de todos os agentes educativos se restrinjam em implementar o que já foi pensado pelo órgão dirigente, sem que seja oportunizado tempo e espaço para a construção de uma proposta de educação diferenciada. Para tentar entender se os participantes compreendem a dimensão de um currículo voltado à diversidade sociocultural existentes nas escolas do campo que possibilite dinamizar os fazeres e as aprendizagens que se concretizam nas salas, perguntamos aos mesmos como concebem um currículo diferenciado, os mesmos se posicionaram da seguinte forma:

Acredito que o currículo diferenciado vem para contemplar uma realidade própria do campo, onde se deve incluir problemáticas próprias dentro dos conteúdos, sendo possível trabalhar isso em todas as disciplinas fazendo a interpretação do aluno ficar mais próxima (Coord. Ped. EP).

O currículo diferenciado para a Escola do campo, eu acredito que além de você trabalhar os conteúdos mínimos da grade curricular, seria você acrescentar nas suas aulas conteúdos que fosse relevante à realidade do aluno; fossem condicente com o contexto na qual o aluno está inserido. Ou seja, além do currículo mínimo você trabalhar também aquilo pela qual o aluno está ali constantemente em convívio, sua vida, sua rotina diária, o seu habitat, ou seja, relacionar os conteúdos que você tem para aplicar para o aluno e acrescentar, junto a esse currículo, a realidade do aluno, o contexto na qual ele vive (Diretora Escolar). 
A essa questão, a Coordenadora pedagógica Rosângela que acompanha as ações da escola investigada, defende que o currículo que consiga "atender as especificidades dos nossos alunos. Para nós que temos a questão geográfica e diversificada do período letivo, com várias dificuldades de aprendizagem [...], o currículo tem que completar estas dificuldades apresentadas". O professor Gilberto respondeu que entende o currículo diferenciado como "aquele que atende as necessidades do aluno, respeitando as diferenças e as dificuldades que os alunos do campo enfrentam".

Os posicionamentos acima evidenciam a estreita relação do currículo escolar com contexto das crianças do campo, porém, quando discutimos o currículo diferenciado, não é suficiente somente incluir esse ou aquele saber. Não se dão conta que, trabalhar com a perspectiva do currículo diferenciado, pressupõe analisar o currículo como um instrumento político-cultural; como elemento central da organização escolar em que perpassam conhecimentos produzidos pela humanidade orientados por uma ideia de cultura geral em detrimento à diversidade de culturas existentes no campo. Assim, enquanto não houver o entendimento do "currículo como forma de contestação, conflito e resistência ao processo de reprodução social, às finalidades de padronização e massificação" (TAFFAREL; ESCOBAR; PERIN, 2010, p. 190); as transformações do trabalho pedagógico das escolas do campo não conseguem se materializar.

É preciso entender que essa relação entre currículo mínimo e a incorporação da realidade dos alunos, conforme apontadas pela Diretora e pela Coordenadora da Escola Polo não ocorre de forma isolada, ilustrativa ou esporádica, mas precisa ser realizado um planejamento pedagógico que possibilite essa prática articulada aos princípios que orientam articulação entre a teoria pedagógica e projeto histórico das populações campesinas, com as condições concretas da escola e do coletivo escolar, como bem destaca Caldart (2004, p. 42): "Educar é ajudar a construir e fortalecer identidades: desenhar rostos, formar sujeitos. Isso tem a ver com valores, modo de vida, memória, cultura". 
Quanto à questão referente às possíveis dificuldades em trabalhar com o currículo diferenciado nas escolas do campo, os participantes da pesquisa responderam o seguinte:

A dificuldade encontra-se na aceitação do professor em adaptar seus exercícios para situações cotidianas e locais, fato esse que se presencia na rotina do uso do livro didático (Coord. Ped. EP).

Uma das dificuldades de se trabalhar com o currículo diferenciado, talvez seria até a aceitação por partes dos professores que muita vezes se prendem ao currículo mínimo, mas tirando disso, eu acredito que não há dificuldade nenhuma, desde que, trabalhando dessa forma a aula se torna mais interessante porque você estará ensinando aquilo que o aluno quer aprender (Diretora Escolar).

Nas falas das representantes da equipe gestora da escola polo há a incidência de não aceitação dos professores quanto à responsabilidade de implementar práticas curriculares diferenciadas centradas na valorização e respeito aos saberes tradicionais das populações do campo. É visível o entendimento por parte dessas profissionais quanto às adaptações dos conteúdos dos livros didáticos em relação ao contexto do campo. Ao pensarem dessa forma, se eximem das atribuições que lhes conferem o cargo de coordenação e gestão escolar, responsabilidades essas que dentre outras, a de propor a elaboração currículos específicos para a realidade do campo - a vida produtiva, cultural, religiosa e política do campo. Ou seja, pensar o currículo escolar não é somente responsabilidade do docente, mas é organização de um processo formativo democrático da Escola do Campo propiciando a aproximação entre escola e realidade local, envolvendo as famílias e os movimentos sociais,

Com isso, a gestão democrática inclui a possibilidade do professor participar das reuniões comunitárias e abrigar, na escola, assembleias gerais da comunidade. Desta forma, a escola pode se tornar um espaço para Simboliza, pois, a intenção das questões e a própria forma/metodologia da coleta de dados não é plenamente adaptada para informações mais detalhadas, encontros da comunidade e dos movimentos sociais como uma das formas de estímulo à participação de todos na vida escolar (GRACINDO, 2006, p.46).

Para o professor Gilberto, as dificuldades que enfrenta em seu fazer pedagógico na perspectiva de um currículo diferenciado, são referentes "a falta 
de opções de materiais didáticos condizentes com o meio em os alunos que vivem, a acessibilidade, a evasão escolar etc". Quanto à Coordenadora Pedagógica Rosângela, nos disse que as dificuldades estão presentes desde a organização pedagógica das escolas do campo, pois as turmas são multiseriadas, o que representam: "várias dificuldades de aprendizagem e não tem como atender cada dificuldade dos nossos alunos e, ainda, temos a questão ambiente escolar, que não favorece". Finaliza seu relato dizendo que há outros aspectos que também podem comprometer a implementação de uma formação que contemple as questões socioculturais das pessoas que vivem e trabalham no campo, à medida que "temos a questão dos materiais pedagógicos, materiais didáticos que também ainda sofre bastante carência com relação a esses materiais pedagógicos".

Como é possível perceber a partir dos posicionamentos dos participantes, o desenvolvimento de um currículo diferenciado esbarra tanto na organização das escolas em turmas multisseriadas, como na escassez de materiais didáticos que dificultam o trabalho; contudo, não nomeiam como dificuldade a ausência de um planejamento da ação educativa e de um projeto pedagógico em que a educação do campo seja amplamente discutida, pois, os aspectos apresentados em suas falas revelam os problemas que as escolas do campo enfrentam diante da desresponsabilização do Poder Público, conforme destaca Hage (2011), que interfere diretamente no trabalho do professor e na formação dos estudantes e, enquanto não for pauta de debate e denúncias, irão permanecer.

Principalmente porque as mazelas que envolvem a realidade
das escolas e turmas multisseriadas são muito antigas e
profundas. Elas resultam do fato de que as questões
educacionais vivenciadas por educadores e estudantes dessas
escolas e turmas, historicamente, não têm sido incluídas na
pauta das políticas educacionais, o que significa dizer que
condições de infraestrutura, processos de gestão, projeto
pedagógico, currículo, metodologias de ensino, materiais
pedagógicos, avaliação e formação de seus educadores têm
sido pouco considerados pelo poder público, pela academia e
pelos movimentos sociais do campo (HAGE, 2011, p. 106).

Isso significa dizer que essas situações devem ser discutidas no espaço escolar, visto que são resultados de ausências de investimentos dos governantes que negam acesso e à permanência em promover uma educação 
de qualidade para os povos do campo, contrariando tanto dispositivos legais, como cerceiam os direitos e os conhecimentos aos qual a classe trabalhadora tem direito. Essas práticas somente promovem a homogeneização dos processos educativos, como atesta Arroyo (2012).

Em relação à questão que fizemos aos profissionais da educação a respeito da adoção de um calendário letivo diferenciado de acordo com o que preconiza a LDB 9394/96 no artigo 23, a Coordenadora Márcia respondeu que as escolas do campo no município de Placas seguem o padrão municipal, ou seja, a Secretaria Municipal de Educação segue um único calendário para atender às escolas da cidade e do campo. O professor Gilberto respondeu também que não há um calendário diferenciando e disse ainda que "[...] precisa ser mais discutido e implantado realmente" (Professor de LP e LE).

Isso contraria o que determina tanto a LDB quanto as Diretrizes para a Educação Básica do Campo - Parecer CNE/CEB n 36/2001 e Resolução CNE/CEB $n^{\circ} 1 / 2002$, que em seu artigo $7^{\circ}$ institui:

É responsabilidade dos respectivos sistemas de ensino, por meio de seus órgãos normativos, regulamentar as estratégias específicas de atendimento escolar do campo e a flexibilização da organização do calendário escolar, salvaguardando, nos diversos espaços pedagógicos e tempos de aprendizagem, os princípios da política da igualdade (BRASIL, 2002).

Em relação à resposta dada pela diretora escolar, esta relatou que a escola em que trabalha "[...] usa um calendário diferenciado, até porque cada escola tem sua realidade. Então é necessário ter seu calendário diferenciado" (Diretora Escolar). Posicionamento compartilhado pela Coordenadora Pedagógica das Escolas Anexas, quando afirma que quando há necessidade, é adotado "um calendário diversificado diferente que venha atender os alunos, àqueles que principalmente não conseguem chegar até a escola”. Para essa profissional, esse calendário "diferente" é criado para atender os alunos em situações circunstanciais, ou seja, no período chuvoso quando há problema com a trafegabilidade das estradas locais em que pode ocorre, por exemplo, a suspensão das aulas, "mas não é algo que acontece com frequência, é muito difícil, nem sempre isso acontece aqui. Mas quando há necessidade a escola faz um calendário diferenciado". 
Porém, o entendimento que temos acerca do calendário diferenciado situa-se em outra dimensão. Posicionamento que destoa da resposta que a coordenadora da própria escola nos deu, pois no período de chuva, as aulas são suspensas; fato que ocorre com frequência região da transamazônica no período das chuvas e que afeta diretamente os estudantes do meio rural. As aulas de reposição são geralmente realizadas aos sábados, que além de comprometer o aprendizado, concorre para que os 200 dias letivos e as quatro horas diárias de aula previstos na legislação não consigam ser cumpridos integralmente. Diante disso, percebemos a necessidade de implementar a gestão escolar nos princípios democráticos, bem como a participação efetiva do Conselho Escolar, que tem a competência de trazer contribuições significativas para algumas questões que abrangem a organização do trabalho pedagógico nas escolas do campo, de modo possibilitar o garantido em lei, pois,

A escola do campo, o sistema educativo do campo se afirmará na medida em que se entrelaçarem com a própria organização dos povos do campo, com relações de proximidade inerentes à produção camponesa - a vizinhança, as família, os grupos, enraizar-se e aproximar as formas de vida centrada no grupo, na articulação entre as formas de produzir a vida (ARROYO, 2006, P. 114).

Em relação ao questionamento referente à adoção de um currículo que introduza aspectos relacionados à identidade sociocultural das populações que moram e trabalham no campo, obtivemos os seguintes posicionamentos:

O uso da BNCC fecha um pouco a interpretação de alguns professores, mas a adequação à realidade se faz necessário atentar a esse olhar (Coord. Ped. EP).

Estão sim, se o nosso currículo apresenta aspecto da identidade regional, ele apresenta de acordo com aquilo que agente planeja, porque dentro do currículo mínimo não, tendo em vista que o currículo mínimo ele é nacional, e a gente tem que inserir dentro dele aquilo que contempla a nossa realidade, a nossa região e os aspectos regionais da nossa realidade (Diretora Escolar).

Sobre essa questão, o Professor Gilberto relatou que foi criado um currículo que é utilizado por todo o município, "mas sem especificar as diferenças, embora se diz ser flexível" (Professor de LP e LE). Este se refere às 
matrizes curriculares que foram elaboradas pela SEMEC, e que é referência para as escolas e professores realizarem os planejamentos pedagógicos..

Para a Professora Rosangela, Coordenadora das Escolas Anexas, acredita que "o currículo que nós utilizamos tem aspecto da nossa cultura paraense". Porém, entende que mesmo os conteúdos escolares apresentarem características da cultura paraense, reconhece que há limites, pois "O currículo é muito diversificado e que contempla todo o Brasil e muito pouco a nossa região".

Para complementar essa questão, perguntamos sobre a existência de uma proposta pedagógica elaborada de acordo com as Diretrizes Curriculares para a Educação Básica do Campo - Resolução CNE/CEB n 1/2002, os participantes da pesquisa apresentaram as seguintes falas:

A proposta curricular no município segue no ciclo a orientação do PNAIC e nos anos maiores segue a BNCC, não sendo realmente olhadas com o olhar necessário para as escolas do campo e sim seguindo um padrão (Coord. Ped. EP).

A gente segue um currículo diferenciado, a gente faz um trabalho no início do ano em equipe, e a partir desse estudo é colocado o currículo mínimo baseado nas diretrizes sim com certeza (Diretora Escolar).

Segundo consta esta proposta curricular é discutida no âmbito municipal, mas na escola, desconheço (Professor de LP e LE).

Utiliza-se o mesmo currículo, porém com algumas adaptações para as escolas do campo que venha atender as especificidades de cada uma, mas o currículo é o mesmo, é feito adaptações (Coord. Ped. EA).

Novamente vemos aqui a compreensão do currículo e da proposta pedagógica da escola restrita às adequações precárias dos conteúdos, fazendo com que o conhecimento universal prescrito nos documentos oficiais, que traz em sua essência, a rigidez e a naturalização da organização dos tempos e espaços escolares pautado ainda no paradigma seriado urbano de ensino, como observa Hage (2011), seja efetivada hegemonicamente nas escolas rurais sem muitos questionamentos, invisibilizando diversidade de vivências dos tempos e espaços dos grupos sociais presentes nesse espaço. Segundo Gomes (2007), essa forma de pensar a dinâmica escolar faz com que, 
Os currículos incorporam uma organização espacial e temporal do conhecimento e dos processos de ensino-aprendizagem. A rigidez e a naturalização da organização dos tempos e espaços escolares entram em conflito com a diversidade de vivências dos tempos e espaços dos alunos e das alunas (GOMES, 2007, p, 37).

Ao indagarmos sobre quais seriam as orientações dadas pela SEMEC com relação ao desenvolvimento do currículo escolar e suas áreas de conhecimento dirigido às escolas do campo, estes responderam que:

Não recebemos nenhuma orientação cientifica relacionada ao campo. (Coord. Ped. EP).

As orientações que a gente recebe da SEME é que todo currículo escolar ele tem que ter como base de planejamento a prática, então agente sempre se reuni início de ano, e a partir dessa prática agente vai analisar pratica entre o nosso conhecimento cotidiano, e os conceitos sentidos no ambiente da escola, e a partir daí agente planeja nossas ações discentes no decorrer do ano juntamente com os demais profissionais da educação. Então ele é sempre feito uma orientação inicio de ano e decorrer de ano com encontros e formações más sempre buscando planejar a partir da pratica e conhecimento que a gente tem, e colocando a questão entre o conhecimento o cotidiano e os conceitos sentidos no ambiente da escola, essas são as orientações que recebemos da SEME durante todo o ano (Diretora Escolar).

O currículo como todos sabem, é muito complicado no nosso município. A SEMED cobra muito, mas a orientação específica a cada disciplina fica muito vaga. Geralmente é elaborado pelos professores de cada disciplina baseando em currículos anteriores (Professor de LP e LE).

Todas as orientações são voltadas à qualidade do ensino, fazer valer o currículo comprometido dos dias letivos, para que venha efetivar a qualidade do ensino, ao mesmo nível de alunos da zona urbana e rural. Portanto, fazem-se essas adaptações para que a qualidade do ensino seja a mesma (Coord. Ped. EA).

As respostas dos participantes convergem para um entendimento que as propostas pedagógicas das escolas do campo são uma mera extensão daquelas desenvolvidas nas escolas da cidade, reforçando a visão que o modelo pretendido de sucesso escolar urbano é a referencia para os estudantes do campo. Esse paradigma leva a escola e aos professores a estabelecer comparações entre os modos de vida urbanos e rurais, entre as escolas da cidade e as do campo, impondo como parâmetro de propostas pedagógicas as 
mesmas praticadas nos centros urbanos. Ressaltamos que a proposta pedagógica precisa ser compreendida como uma construção coletiva orientada por ato educativo emancipatório. Para Veiga (2005, p. 15), o PPP possibilita à escola organizar todo o de trabalho pedagógico de forma participativa de modo a "repensar da estrutura de poder da escola".

Nessa acepção, precisamos defender um currículo diferenciado voltado à educação do campo como uma construção coletiva em permanente reconstruir, em real e contínuo movimento nos dizeres de Caldart et all (2012, p. 13).

A essência da Educação do Campo não pode ser apreendida senão no seu movimento real, que implica um conjunto articulado de relações (fundamentalmente contradições) que a constituem como práticalprojetolpolítica de educação e cujo sujeito é a classe trabalhadora do campo.

De acordo com Gomes (2007), é preciso superar esses posicionamentos que submetem as aprendizagens dos estudantes ao enquadramento institucional que nega a diversidade, que conforma identidades. Propõe como alternativa a elaboração de propostas que tenha como centro, os sujeitos. Em suas palavras,

Um bom caminho para repensar as propostas curriculares para infância, adolescência, juventude e vida adulta poderá ser uma orientação que tenha como foco os sujeitos da educação. A grande questão é: como o conhecimento escolar poderá contribuir para o pleno desenvolvimento humano dos sujeitos? Não se trata de negar a importância do conhecimento escolar, mas de abolir o equivoco histórico da escola e da educação de ter como foco prioritariamente os "conteúdos" e não os sujeitos do processo Educativo (GOMES, 2007, p. 33).

Para Hage (2011), essa prática reforça a adoção de conteúdo e metodologia que somente desvalorizam o seu modo de vida, sua cultura das populações camponesas e supervalorizam o modo de vida na cidade. Considera ser de extrema importância superar essa tendência urbanocêntrica e buscar alternativas consolide o projeto de desenvolvimento educacional democrática,

Implica, também, realizar uma "escuta sensível" ao que os professores e estudantes vêm realizando no cotidiano da escola, destacando as atividades bem-sucedidas, valorizando as boas práticas educativas e refletindo sobre as experiências que não se efetivam adequadamente, para ressignificar, com eles, os 
sentidos de currículo, projeto pedagógico, educação, escola... Enfim, repensar as práticas e formular novas propostas sintonizadas com a realidade dos sujeitos do campo, ou seja, do lugar dos sujeitos do campo, sem apartá-los do mundo global e do contexto urbano, com os quais o território do campo interage continuamente, constituindo-se sua identidade/subjetividade a partir dessa interação (HAGE, 2011, p. 108).

Com isso, esse autor defende que os currículos das escolas do campo devem que considerar os alunos como sujeitos do conhecimento e atores históricos e sociais, por meio do possibilitando do diálogo entre os diferentes saberes que se intercruzam no cotidiano da escola do campo.

\section{Considerações finais}

Pensar em uma proposta centrada no currículo diferenciado que valoriza a cultura e o saber popular representa uma alternativa de trabalhar a diversidade cultural nas escolas do campo no município de Placas/PA. Com intuito de valorizar as identidades dos diferentes sujeitos coletivos que vivem e trabalham no campo demanda o reconhecimento pelos profissionais da educação e por toda a sociedade brasileira do potencial socioeconômico que o território do campo representa.

A construção de um currículo diferenciado e voltado para a comunidade campesina pressupõe considerar inicialmente a história da mesma no diagnóstico a ser realizado para o Projeto Político Pedagógico da escola; a trajetória de vida dos moradores da localidade, de suas reivindicações, suas tradições. Significa dizer que a escola é um espaço de vivencias e práticas socioculturais que atenda de fato a realidades das comunidades camponesas, sua organização social e cultural.

Como vimos, e direito dos discentes estudarem em uma escola que tenha uma proposta pedagógica que trabalhe sua diversidade cultural de acordo com o que está na Lei de Diretrizes e Bases (LDB) 9394/96. O Projeto Político Pedagógico é um documento que estabelece medidas e objetivos para desenvolver na escola, nele tem que estar todas problemáticas possíveis que engessam o ambiente escolar. Nessa perspectiva, essa lei deixa bem claro da 
importância do PPP pensado para e pelas as escolas que atendem os filhos de camponeses de forma participativa.

Os conteúdos escolares não podem ser pautado em um modelo urbano, que desvaloriza os saberes tradicionais e reforçam a ideia de o campo ser um lugar sem valor, um ambiente triste e sem cultura; aspectos reproduzidos ainda nos livros didáticos, que silenciam o modo de vida dos diferentes povos que vivem e trabalham campo da região amazônica. Portanto, através dos argumentos apresentados percebe-se a necessidade que o alunado tem de conhecer a sua realidade, e o docente precisa ter o conhecimento do ambiente em que vivem, e assim valorizando e desenvolvendo projetos que venham aprimorar e alavancar este lugar.

\section{Referências}

ARROYO, M. Currículo, território em disputa. 5ed. Petrópolis: Vozes, 2012.

ARROYO, Miguel Gonzalez. A educação básica e o movimento social do campo. In.: ARROYO, Miguel Gonzalez; CALDART, Roseli Salete; MOLINA, Mônica Castagna (Orgs). Por uma educação do campo. 4. ed. Petrópolis, RJ: Vozes, 2009.

ARROYO, Miguel. A escola do campo e a pesquisa do campo: metas. In: MOLINA, Mônica (org). Educação do campo e pesquisa: questões para reflexão. Brasília, MDA, 2006.

BRASIL, Constituição Federal, 1988. Texto constitucional promulgado em 5 de outubro de 1988. Brasília: Senado Federal, Subsecretarias de Edições Técnicas, 2008.

BRASIL. Lei n. 9.394, de 20 de dezembro de 1996. Estabelece as diretrizes e bases da educação nacional. Diário Oficial [da] República Federativa do Brasil, Poder Legislativo, Brasília, DF, 23 dez. 1996.

BRASIL. Ministério da Educação. Resolução CNE/CEB n ${ }^{0} \mathbf{1}$, de 3 de abril de 2002. Institui Diretrizes Operacionais para a Educação Básica das Escolas do Campo. Diário Oficial da União, Poder Legislativo, Brasília, DF, 9 abr. 2002.

BRASIL, Ministério da Educação CNE/ CEB. Diretrizes Complementares para o atendimento da Educação Básica do Campo. Resolução CNE/ CEB Nº 2. Brasília-DF, de 28 de Abril de 2008.

BRASIL. Decreto 7.352, de 4 de novembro de 2010. Dispõe sobre a política de educação do campo e o Programa Nacional de Educação na Reforma Agrária - 
PRONERA. Diário Oficial da União, Poder Legislativo, Brasília, DF, 4 de nov. 2010.

CALDART, Roseli Salete; PEREIRA, Isabel Brasil; ALENTEJANO, Paulo e FRIGOTTO, Gaudêncio. Dicionário da Educação do Campo. Rio de Janeiro, São Paulo: Escola Politécnica de Saúde Joaquim Venâncio, Expressão Popular, 2012.

CALDART, R. S. Caminhos para a transformação da Escola: reflexões desde práticas da licenciatura em Educação do Campo. Expressão Popular. Cadernos do Iterra, ano X, $\mathrm{n}^{\circ} 15,2010$.

CALDART, Roseli Nunes. Sobre a educação do campo. In: SANTOS, Clarice (Org.). Educação do campo: Campo-políticas públicas-educação. Brasília, DF: INCRA; MDA, 2008.

CALDART, Roseli Salete. Por uma educação do campo: traços de uma identidade em construção. In: ARROYO, Miguel Gonzalez; CALDART, Roseli Salete; MOLINA, Mônica Castagna (Org.). Por uma educação do campo. Petrópolis: Vozes, 2004. p. 147-158.

CALDART, Roseli Salete. Por Uma Educação do Campo: traços de uma identidade em construção. In: KOLLING, Edgar Jorge; CERIOLI, Paulo Ricardo; CALDART, Roseli Salete (Orgs.). Educação do Campo: identidade e políticas públicas. Brasília, DF: Articulação Nacional Por Uma Educação do Campo, 2002

FERNANDES, Bernardo Mançano. Diretrizes de uma Caminhada. In: ARROYO, Miguel Gonzalez et al. Por uma educação do campo. 3. ed. Petrópolis: Vozes, 2006.

GIL, Antonio Carlos. Como elaborar pesquisa. São Paulo: Atlas, 2006.

GIMENO SACRISTÁN, J. O currículo: uma reflexão sobre a prática. 3.ed. Porto Alegre: Artmed, 2000.

GOMES, Nilma Lino. Indagações sobre currículo : diversidade e currículo. Organização do documento Jeanete Beauchamp, Sandra Denise Pagel, Aricélia Ribeiro do Nascimento. - Brasília : Ministério da Educação, Secretaria de do campo. Petrópolis: Vozes, 2007.

GRACINDO, Regina Vinhaes. Conselho Escolar e Educação do Campo. Brasília: Secad.MEC, 2006.

HAGE, Salomão Mufarrej. Por uma escola do campo de qualidade social: transgredindo o paradigma (multi)seriado de ensino. Brasília, v. 24, n. 85, p. 97113, abr/ 2011.

MINAYO, Maria Cecília de Souza. Ciência Tecnologia e arte Desafio da Pesquisa Social. In: MINAYO, M.C.S. GOMES, S. F. D. R. Pesquisa Social: Teoria, Método e Criatividade. $21^{\circ}$ ed. Petrópolis, Rj: Vozes. 2002. 
MOLINA, M. C.; SÁ, MOURÃO, L. Escola do Campo. In.: CALDART, R. S.; PEREIRA, I. B.; ALENTEJANO, P.; FRIGOTTO, G. Dicionário da educação do campo. Brasil. São Paulo: Expressão Popular, 2012. p. 257-264.

MUNARIM, Antonio,LOCKS Geraldo Augusto. Educação Do Campo: contexto e desafios desta política pública. In: Olhar de professor, Ponta Grossa, 15(1): 7789, 2012. Disponível em http://www.uepg.br/olhardeprofessor

SILVA, T. T. da. Documentos de Identidade: uma introdução às teorias do currículo. 2 ed. Belo Horizonte: Autêntica, 2009.

TAFFAREL, Celi Nelza Z.; ESCOBAR, Micheli Ortega; PERIN, Teresinha de Fátima. Currículo. IN: TAFFAREL, Celi Nelza Z.; SANTOS JR, Cláudio de Lira; ESCOBAR, Micheli Ortega. Cadernos didáticos sobre educação do campo. Salvador: Ministério da Educação, 2010.

VEIGA, I. P. A. Projeto político pedagógico: uma construção coletiva. In: (Org.). Projeto político-pedagógico da escola: uma construção possível. 15. ed. Campinas, SP: Papirus, 2005.

\section{Sobre os autores}

\section{Irlanda do Socorro de Oliveira Miléo}

irlanda@ufpa.br

Licenciada em Pedagogia, Mestre em Educação/Políticas Públicas Educacionais e Doutora em Educação: Currículo pela Pontifícia Universidade Católica - São Paulo (2013). É professora do Curso de Licenciatura em Educação do Campo da Universidade Federal do Pará/Campus Universitário de Altamira, onde atua nas áreas de Didática, Currículo, Avaliação e Estágio Supervisionado. Coordena o Grupo de Estudo e Pesquisa em Educação, Currículo e Cultura (GEPECC).

\section{Raquel da Silva Lopes}

ralopes@ufpa.br

Licenciada em Letras/Português, Mestre em Letras/Linguística e Doutora em Ciências Sociais/Antropologia. É professora do Curso de Licenciatura em Educação do Campo, da Universidade Federal do Pará/Campus de Altamira, onde atua nas áreas de linguística, ensino de línguas, metodologias de ensino e educação diferenciada.

\section{Célio Lima Machado}

celiomachadoufpa@gmail.com

Licenciado em Educação do Campo com ênfase em Linguagem e Códigos pela Universidade Federal do Pará/Campus Universitário de Altamira. Atuou como professor de língua portuguesa no período de 2014 a 2019 em turmas dos anos finais do Ensino fundamental da rede de ensino do Munícipio de Placas, Estado do Pará. 